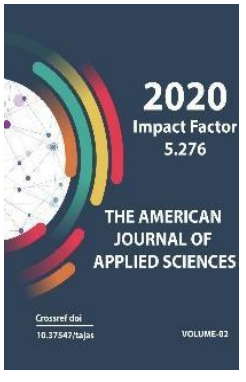

Journal Website: http://usajournalshub.c om/index,php/tajas

Copyright: Original content from this work may be used under the terms of the creative commons attributes 4.0 licence.

\section{Bisingular Integral In The Space Of Summable Functions}

Tolliboy Absalamov

Ph.D., Associate Professor, Samarkand State University, Uzbekistan

Buvraziya Fayzullayeva

Ph.D., Associate Professor, Samarkand State University, Uzbekistan

\title{
ABSTRACT
}

It is obtained a Zigmund type estimate for the bisingular integral in the space of Summation functions. It is constructed an invariant functional space based on the inequality. Using the method of successive approximations it is proven the solvability of the nonlinear bisingular integral equation in invariant space.

\section{KEYWORDS}

Bisingular integral operator, Zigmund type estimate, invariant space, summable function.

\section{INTRODUCTION}

The classical boundedness theorem of singular operator with the Hilbert kernel in space $L_{-}(p$ ) (p>1), it was proved by N.H. Luzin in [6] and M.Riesz in [16] for the cases $p=2$ and $p>1$, respectively.

Subsequently, this result was carried over in a number of papers for fairly wide classes of Jordan rectiable curves. A detailed prehistory of this issue is available in the work [9], also in the works of A.P. Calderon [11] ,[12], and [13].

To study the special integral 
$(-\infty<a<b<+\infty)$ with the summable density in the work [4], [10] for a function u L_p $p^{\wedge} \operatorname{loc}(a, b)$, where L_p^loc $(a, b)$ - is the set of functions, summable with the degree $p$ in any compact segment of the interval $(a, b)$. The characteristics were introduced a $\mathrm{d} \mathbf{i}$ the ase $<<+\infty$ it is ed estimates $u$ ) $u$ )) by (u), 『』_p(u)).

In the limiting case $f \quad=\infty$ a d u $\quad \mathrm{C}[\mathrm{a}, \mathrm{b}]$ these results were obtained in [3], [7], it was shown that estimates [2] in a certain sense are unimprovable. In [5] using $M$. Riesz's theorem about the bounded action

was a work of L. Cesari [14]. He proved that if

Following L. Cesari, I.E. Zak [5] in his work also showed that the class of functions $\left.\left.\mathrm{H} \delta \wedge^{\wedge} \delta 2^{\wedge} \alpha\right)\right)^{\wedge} 2$ is $\mathbf{t} \mathbf{i}$ a ia $t$ with fa $\quad$ at $u$ i thes ae $\_p(a, b)$ the results are obtained in [1], [2].

One of the first papers, dedicated to the repeated special integral with the Hilbert kernel

then was proved that the classes of functions 
are invariant with respect to the operator B.

where the function,

For the we introduce the characteristic

\section{RESULTS}

Consider a bisingular integral of the form

and . 
where

$$
=1,2 \text {. }
$$

Using, it was proven

Teopema 1. Let .......................................................................................... Then from convergence of correspondence integrals it holds the following inequality

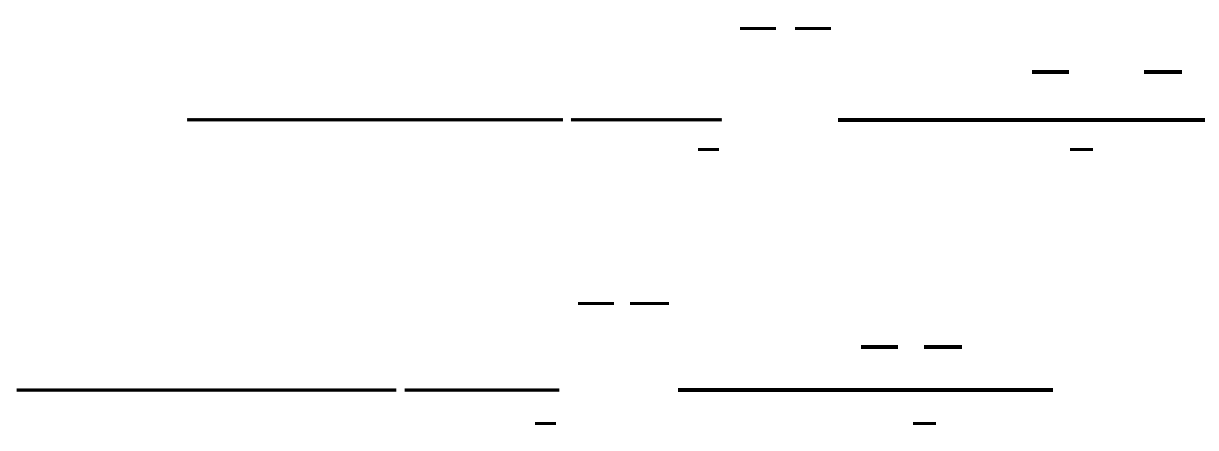



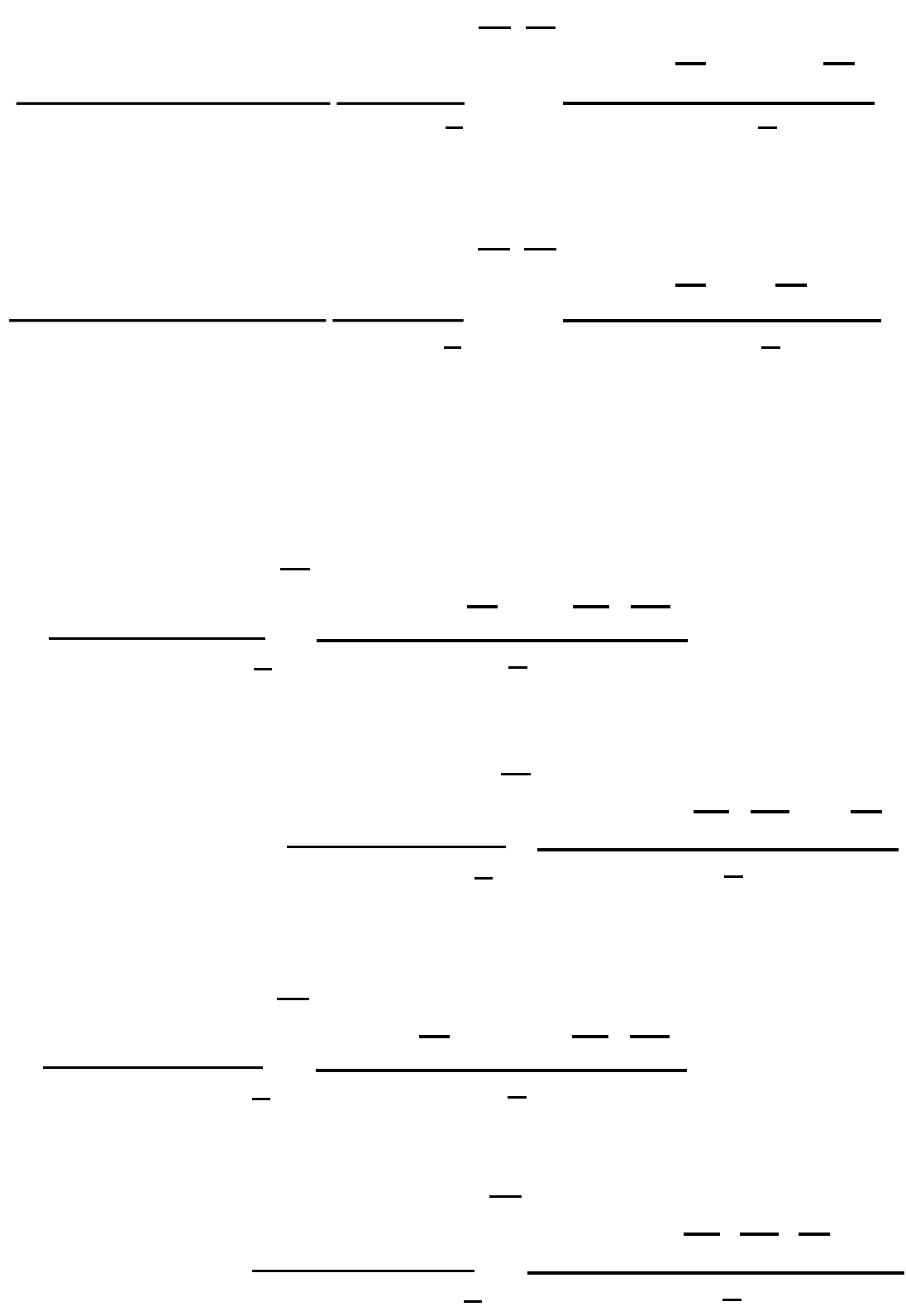

whe e the sta $\mathrm{t} c$ is de e de $t$

p.

Moreover, it is obtained estimates $u$

) $\mathrm{u}$ ) , u ). We denote by Cthe set $f$ sitie fu ti $s \varphi \xi \eta$

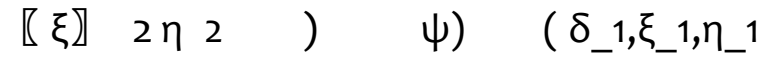

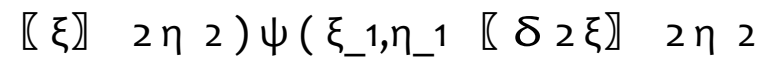
)$\left.\psi \delta \xi \eta \quad \begin{array}{lll}\delta_{2} & 2 \xi] & 2 \eta 2\end{array}\right)$ defied $\quad f \quad \delta i \xi i \quad)$ $\eta i>0 \xi i$ ) $+\eta \quad i=I \quad i=b_{-} i-a_{-} i \quad i=1,2$, and such 
that the fu tis $\varphi \psi \quad, \psi, \psi$ almost decreasing in $\xi_{1} 1, \xi_{2} 2$ (uniformly by other variables), the functions $\psi, \psi, \psi$ almost increasing in $\delta \_1, \delta \_2$ (uniformly by other variables), the functions

almost decreasing in (uniformly by other variables), last but not less

for
Let
Denote by
the set of functions from such that

there exists constant and

The set

by norm

is a Banach space.

By we denote the set of function

such that the following integrals are convergent
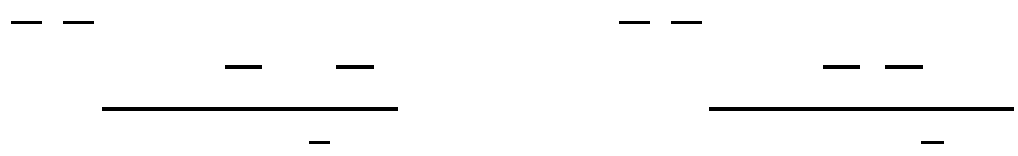
Doi: https://doi.org/10.37547/tajas/Volume02Issue08-04

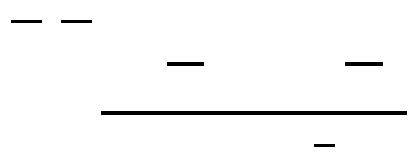

$-$
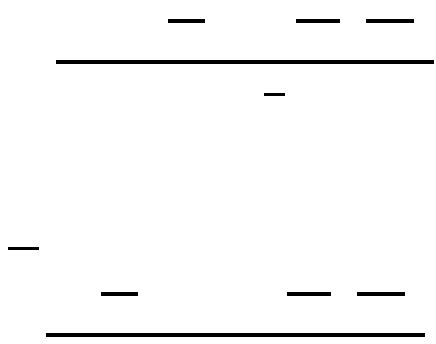

$-$

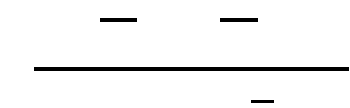

$-$

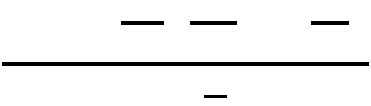

$-$

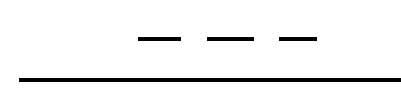

Now, we determine by the set of positive functions satisfying the following conditions:
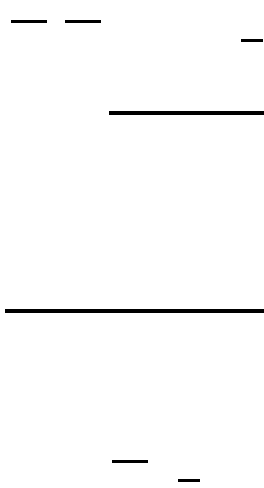


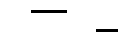

where the constants in expression do not depend on

In a view of definition we say that if

and

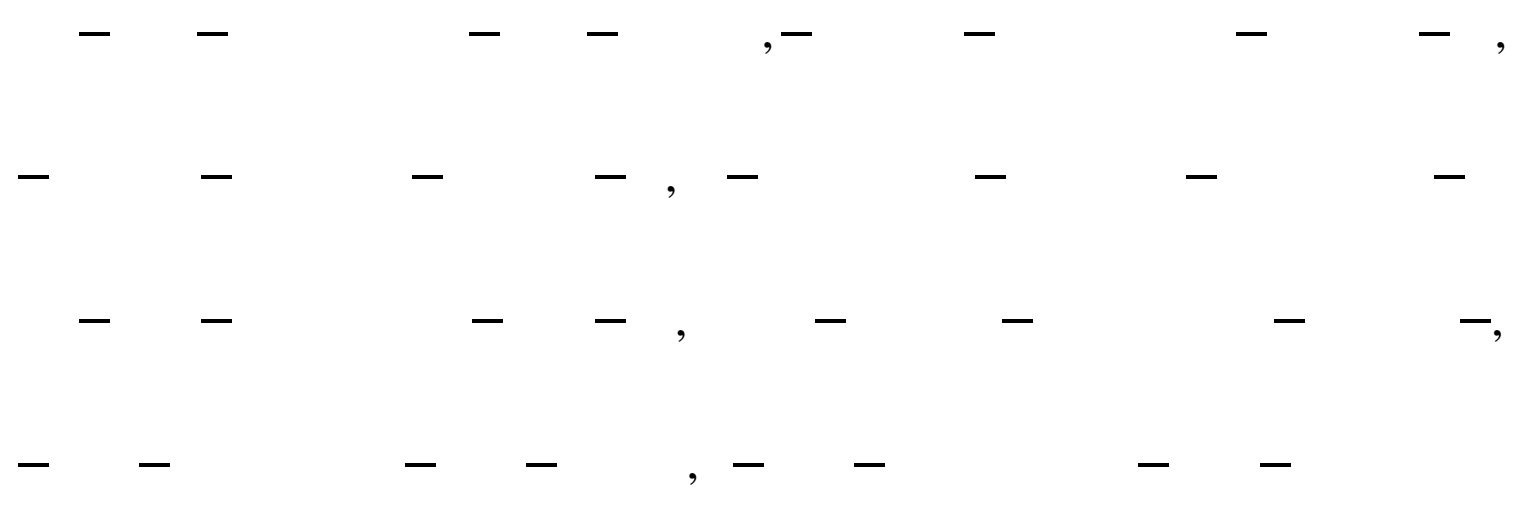

We note that the proof of this last

Tеорема 2. If $\varphi \psi, \psi, \psi)$ о $\mathrm{H}$. he e at $\mathrm{u}$ ma s the s a e H_$(\varphi, \psi, \psi, \psi$ )$^{\wedge}$ Pitself and is bounded. Theorem 2 COMES from the proof of Theorem 1 and by definition of the sets of G_O H_P. 


\section{CONCLUSION}

Using the method of successive approximations it is proven the solvability of the nonlinear bisingular integral equation

in , where the function is defined on and - is a real parameter.

\section{REFERENCES}

1. Abdullaev S.K., Babaev A.A. Some estimates for a singular integral with summable density. Dokl. Akad. Nauk SSSR, 188:2(1969), 263-265.

2. Abdullaev S.K., Babaev A.A. On a singular integral with summable density. Func. anal. and appl., Baku, (1978), 3-32.

3. Babaev A.A. Some properties of a singular integral with a continuous density, and its applications. Dokl. Akad. Nauk SSSR, 170, 5(1966), 255258.

4. Гусейнов Е.Г. Салаев В.В. Особый интеграл по отрезку прямой в пространствах суммируемых функций. Науч. р. МВ и ССО Азерб. ССР серия физ.-мат. наук 979) 8 87.

5. Zak I.E. On conjugate double trigonometric series. Mat.Sb.31, 73(1952), 469-484.
6. Luzin N.N. The Integral and Trigonometric Series, $2^{\wedge}$ nded. Gostekhizdat, Moscow (1951).

7. Салаев В.В. Некоторые свойства особого интеграла. Уч. зап. АГУ им. С.М.Кирова сер. физ.-мат.н. 44 6(1966).

8. Hardy G.H., Littlwood J.E., Polya G. Inequalities. $\quad 2^{\wedge}$ nd ed. Cambridge University Press, Cambridge, 1967.

9. Khvedelidze B. Modern problems of mathematics. Moscow: "VINITI", 7(1975), 5-162.

10. Холмуродов Э. Некоторые оценки для особого интеграла с локально суммируемой плотностью. Уч. зап. АГУ им. С.М.Кирова сер. физ.-мат.н. 6 (1978), 71-80.

11. Jean-Michel Bony. Resolution des conjectures de Calderon et espaces de Hardy generalizes. "Asterisque", 9293(1982), 293-300.

12. Calderon A.P. Cauchy integrals on Lipschitz curves and related operators. Proc. Nat. Acad. Sci. USA, 74(1977), 1324-1327. 
13. Calderon A.P., Calderon C.P., Fabes E., Jodeit $M$. and Riviere N. M. Applications of the Cauchy integral on Lipschitz curves. Bull. Amer. Math. Soc., 84(1978), 287-290.

14. Cesari L. Sulle cerie di Fourier delle funzioni Lipschitziane di piu variable.
Ann. Schola. Norm. Sup.Piza, 7(1938), 279-295.

15. Fefferman R. $A^{\wedge} p$ Weights and Singular Integrals. Amer. J.Math., 110, 5(1988), p.975-987.

16. Riesz M. Sur les fonctions conjugue'es. Math. Z., 27(1928), 218-244. 